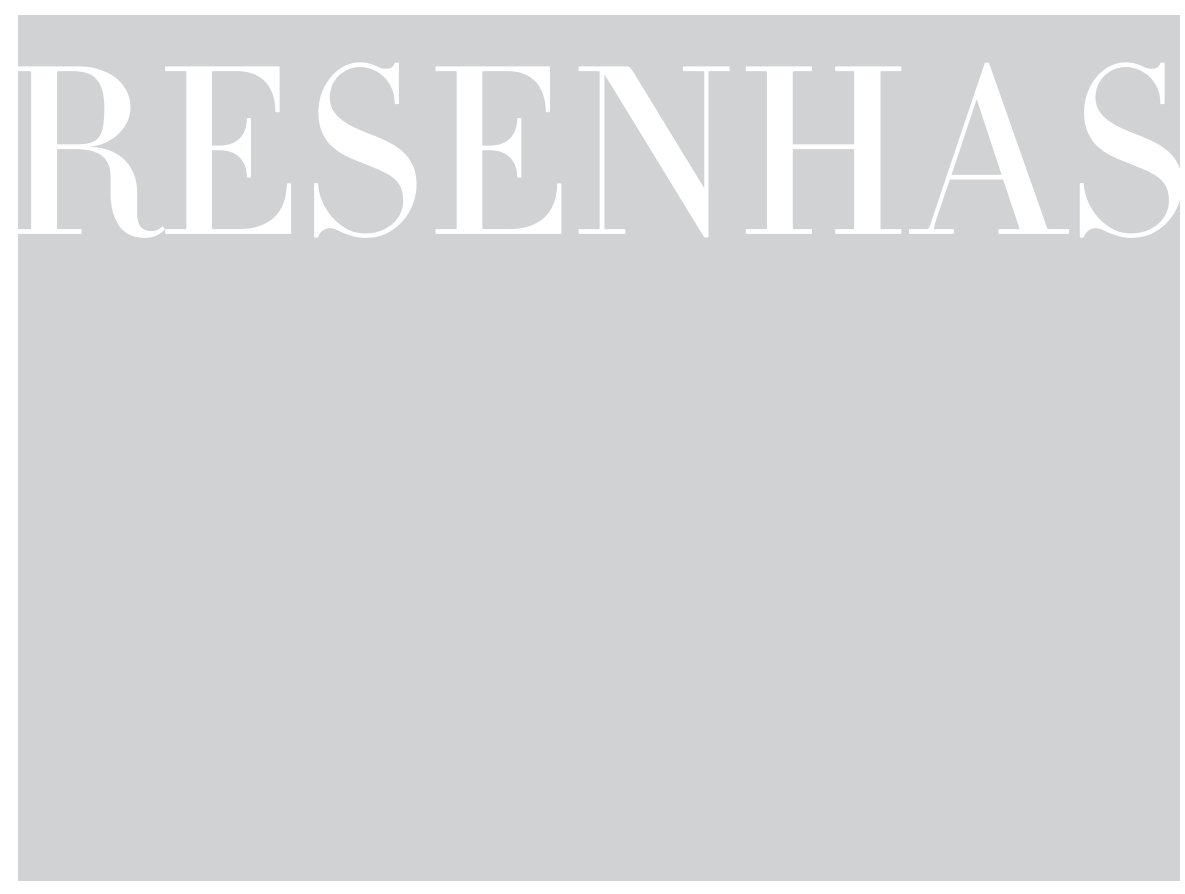

\title{
UM OLHAR DE GÊNERO SOBRE A EDUCAÇÃO FÍSICA ESCOLAR
}

http://dx.doi.org/10.1590/198053143338

ALTMANN, Helena. Educação física escolar: relações em jogo.

São Paulo: Cortez, 2015. 176 p. (Coleção Educação \& Saúde, v. 11)

A compreensão das relações de gênero como um processo capilar que envolve as configurações das masculinidades e das feminilidades, além das mais variadas maneiras pelas quais constituímos nossos corpos, nossas identidades e nossos desejos, remete a muitas áreas do conhecimento, entre elas a educação em geral e, mais especificamente, a educação física escolar.

É nesse terreno que Helena Altmann nos conduz com maestria ao longo do livro Educação física escolar: relações em jogo. Professora da Universidade Estadual de Campinas - Unicamp -, onde atua na Faculdade de Educação Física e no Programa de Pós-Graduação em Educação, a autora tem se dedicado por longos anos à formação e à pesquisa, com ênfase para a análise da educação e da educação física escolar sob a perspectiva de gênero.

O livro nos mostra os meandros da insistente permanência do androcentrismo e da heteronormatividade no mundo do esporte, também presentes no desenho da educação física escolar. Em uma sociedade que já reflete tantos ganhos das lutas feministas, das demandas advindas do movimento LGBT - Lésbicas, Gays, Bissexuais, Travestis, Transexuais e Transgêneros - e da produção de estudos e investigações 
sobre o tema, o controle dos corpos ainda apresenta-se firme, mesmo que muitas vezes sutil.

O esforço de Helena Altmann soma-se às muitas investigações realizadas ao longo das últimas décadas em torno dos desafios concernentes à inclusão da perspectiva de gênero nas políticas públicas de educação, nas reflexões e nas práticas que tratam de educação.

Essa inclusão ainda pode ser considerada recente. Durante toda a década de 1990, vários são os registros sobre as dificuldades para obtenção de financiamento quando as investigações propunham o gênero como categoria de análise para os problemas educacionais. Há pouco mais de uma década, Fúlvia Rosemberg $\left(2001^{1}\right)$ alertava sobre a dificuldade de incorporação do gênero enquanto categoria de análise pela produção acadêmica sobre educação.

Já avançamos de lá para cá, hoje muitos são os estudos na área da educação que possuem por foco a perspectiva de gênero, com evidente aumento de pesquisas que articulam gênero, sexualidade e diversidade sexual. Levantamento sobre a produção acadêmica que articula gênero e educação formal registra, entre 1990 e 2006, 1.213 títulos - entre artigos, dissertações de mestrado e teses de doutorado (VIANNA et al., $2011^{2}$ ). Mas, apesar desse forte crescimento da perspectiva de gênero na produção acadêmica educacional, muitas facetas da educação ainda são carentes de maiores reflexões, entre elas a educação física.

As ponderações trazidas pelo livro em tela somam-se aos esforços realizados e contribuem com análises capazes de apreender as contradições, os avanços e os recuos desse processo. A crítica afiada não embaça o olhar apurado para o longo processo de confrontação de práticas de resistência que procuram enfrentar o padrão de masculinidade hegemônica.

O livro divide-se em duas partes. A primeira, com o título "Gênero, Esportes e Educação Física”, explora os resultados de pesquisas realizadas junto ao Grupo de Pesquisa Corpo e Educação, da Faculdade de Educação Física da Unicamp. Logo no início, a autora destaca o crescimento da presença feminina no esporte. Não despreza, entretanto, a força da permanência de um padrão androcêntrico nas práticas esportivas chanceladas por nossa sociedade, nas imagens veiculadas pela mídia, na aquizição de aprendizagens, habilidades, técnicas e possibilidades corporais distintas, para não dizer antagônicas entre homens e mulheres desde a mais tenra idade. A análise das imagens veiculadas pela mídia mostra, por exemplo, que a indústria de calçados infantis oferece e divulga produtos diferenciados para meninos e meninas. Esses produtos variam: se a ênfase está no desempenho masculino, são mais confortáveis e mais dispostos ao movimento corporal; se o foco é o consumo feminino, o destaque é a estética e a moda, mesmo que

1 ROSEMBERG, Fúlvia. Caminhos cruzados: educação e gênero na produção acadêmica, Educação e Pesquisa, São Paulo, v. 27, n. 1, p. 47-68, 2001. 2 VIANNA, Cláudia; CARVALHO, Marília Pinto de; SCHILLING, Flávia; MOREIRA, Maria de Fátima Salum. Gênero, sexualidade e educação formal no Brasil: uma análise preliminar da produção acadêmica entre 1990 e 2006. Educação e Sociedade, Campinas, v. 32, n. 115, p. 525-545, abr./jun. 2011 
isso signifique prejuízos quanto ao movimento corporal das meninas e, consequentemente, à melhoria das habilidades femininas no esporte.

O livro nos alerta para o fato de que a própria trajetória de inserção das mulheres nos esportes modernos revela um longo processo de proibições. Essa trajetória também indica disputas e contestações de regras e normas legais que vetam a aquisição de práticas corporais específicas voltadas para o bom desempenho feminino nos esportes. Trata-se de um desafio a ser também enfrentado pelas escolas diante da esportivização da educação física escolar.

Importantes questões são debatidas pela autora: a escola e suas aulas de educação física necessitam formar apenas atletas de alto rendimento ou precisam se constituir em espaços mais amplos de aprendizagem e educação corporal? As aulas de educação física devem se reduzir ao jogo de futebol?

A tensão entre a alta especialização e a democratização do acesso à cultura e à educação esportivas pautam a reflexão desse primeiro tópico, que tem parte importante dedicada ao futebol enquanto um forte marcador social que dissemina uma educação corporal ferozmente diferenciada por gênero, e por que não dizer desigual.

A segunda parte, intitulada "Gênero e Educação Física Escolar", tem como foco as relações de gênero vividas por uma professora de educação física em uma escola pública. Helena Altmann elucida o modo como essas relações atravessam o conteúdo e as práticas pedagógicas da educação física, as experiências de meninos e meninas nessas aulas e os jogos olímpicos escolares, assim como recreios, festas, aulas de outras disciplinas, conselhos de classe e reuniões docentes.

A ocupação generificada dos espaços escolares e o esporte como expressão da dominação masculina são fortes exemplos de enfrentamentos masculinos da ordem e das normas presentes na escola. Como diz a autora, “a estratégia predominantemente utilizada pelos meninos para a conquista do espaço era a transgressão”. Contudo, uma vez mais, a apreensão cuidadosa das contradições faz com que a análise escape de polarizações apressadas, ou seja, se meninos enfrentam e meninas usam de cumplicidade, isso não significa que elas necessariamente se submetem. Muito pelo contrário, o texto revela que elas usam a cumplicidade como estratégia consciente de permanência na escola. E é por meio desse outro mecanismo que, nas aulas de educação física, processos de acomodação e resistência marcam o cotidiano dessas meninas, que muitas vezes cruzam as fronteiras de gênero e afirmam-se, no grupo masculino, como boas jogadoras de futebol. O cruzamento dessas fronteiras também era realizado por meninos e meninas nas formas de ser e se relacionar com o grupo, no uso de adornos, nas brincadeiras e até mesmo na inserção das meninas nas práticas esportivas realizadas dentro da escola e nas aulas de educação física. 
Assim, se, por um lado, a educação corporal diferenciada por gênero, disseminada na vida social, separa meninos e meninas em suas práticas corporais, revelando relações de poder que atravessam as experiências de jogo e a ocupação dos espaços escolares, por outro lado, há resistências que acenam para novas possibilidades e vivências de corpos masculinos e femininos.

Essas são as grandes contribuições desse livro e o principal motivo pelo qual recomendo enfaticamente sua leitura, a qual certamente trará uma contribuição significativa para a educação brasileira.

\section{CLÁUDIA PEREIRA VIANNA}

Faculdade de Educação da Universidade de São Paulo - FE/USP - São Paulo, São Paulo, Brasil

cpvianna@usp.br 